\title{
Synthesis and spectral characterization of related compounds of riluzole, an amyotrophic lateral sclerosis drug substance
}

\author{
Bollikonda Satyanarayana,* M. Saravanan, K. Siva Kumari, D. P. Lokamaheshwari, \\ Ch. Sridhar, R. Ravishankar, A. Nageswari, and P. Pratap Reddy \\ Dr Reddy's Laboratories Limited, Bachupalli, Qutubullapur, Rangareddy District-72, Andhra \\ Pradesh, India
}

E-mail: bsn2626@yahoo.com, satyanarayanab@drreddys.com

\begin{abstract}
Riluzole is a benzothiazole derivative, used to treat amyotrophic lateral sclerosis. During the process development of riluzole, nine unknown peaks (related compounds/impurities) were observed in HPLC analysis in the range of 0.05 to $0.15 \%$. These impurity samples were analyzed by LC-MS and the respective peaks were identified at $m / z 177,177,177,234,234,312,255,396$ and 333. Among the nine impurities, six impurities were identified as process-related impurities and the remaining three impurities were assigned to the starting material and its isomers. The six process-related impurities were synthesized and characterized based on their spectral data (IR, NMR and MS).
\end{abstract}

Keywords: Riluzole, amyotrophic lateral sclerosis, glutamate

\section{Introduction}

Riluzole $^{1,2}$ is 2-amino-6-(trifluoromethoxy)benzothiazole and it is used to treat a certain type of nerve disease called amyotrophic lateral sclerosis ${ }^{3,4}$ (Lou Gehrig's disease). Riluzole helps to slow down the progress of this disease and prolong survival. It is thought to work by protecting the nerves in the brain and spinal cord from excess glutamate that may be the cause of nerve damage. Since it is an important drug substance and in order to have knowledge of the impurity profile, we have made a comprehensive study on the impurities generated during the process development of riluzole (Scheme 1). The quality of drug substance is very important to commercialize the product and must be more than $99 \%$. Also, as per the regulatory guidelines, ${ }^{5}$ the acceptable level for known and unknown impurities in a drug substance must be less than 0.15 and $0.10 \%$ respectively. The present article describes the identification, synthesis and characterization of the six process-related impurities of riluzole. 


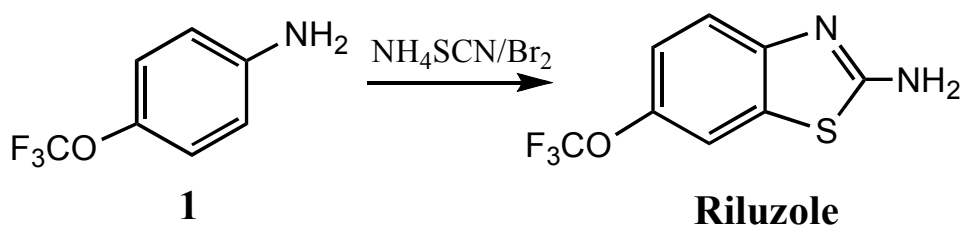

\section{Scheme 1}

\section{Results and Discussion}

During the process development of riluzole, the technical grade material was analyzed by reverse phase HPLC showing nine unknown impurity peaks in the range of 0.05 to $0.15 \%$. The material was also subjected to LC-MS analysis. Thus the molecular weights of nine impurities were identified as 177, 177, 177, 234, 234, 312, 255, 396 and 333. The three impurities having mass number 177 were identified as 4-trifluoromethoxyphenylamine (1) and its regio isomers 2 and $\mathbf{3}$. The other six impurities were identified as 5-trifluoromethoxybenzothiazol-2-ylamine (4), 4trifluoromethoxybenzothiazol-2-ylamine 4-bromoriluzole

(4-bromo-6trifluoromethoxybenzothiazol-2-ylamine) (6), 2-bromo-4-trifluoromethoxyphenylamine (7), 1,3bis-(4-trifluoromethoxyphenyl)thiourea (8) and 2,6-dibromo-4-trifluoromethoxyphenylamine (9). All of the six process-related impurities were synthesized and subsequently characterized by their respective spectral data (IR, NMR and MS). 5-Trifluoromethoxybenzothiazol-2-ylamine (4) and 4-trifluoromethoxybenzothiazol-2-ylamine (5) were synthesized from $\mathbf{2}$ and $\mathbf{3}$ respectively by reacting with bromine and ammonium thiocyanate (Scheme 2). The mass spectra of $\mathbf{4}$ and $\mathbf{5}$ displayed the same protonated molecular ion at $m / z 235$. This suggested that $\mathbf{4}$ and $\mathbf{5}$ could be isomers of riluzole. In the ${ }^{1} \mathrm{H}$ NMR spectrum of 4 , a singlet signal was observed at $\delta=6.83 \mathrm{ppm}$ and two doublets at $\delta=6.65 \mathrm{ppm}$ and $\delta=7.52 \mathrm{ppm}$. From the above spectral data, the structure was confirmed as 5-trifluoromethoxybenzothiazol-2-ylamine (4). In the ${ }^{1} \mathrm{H}$ NMR spectrum of 5, there is no singlet signal for an aromatic proton, doublets were observed at $\delta=6.92 \mathrm{ppm}$ and $\delta=$ $7.54 \mathrm{ppm}$ and doublet of doublets was observed at $\delta=7.32 \mathrm{ppm}$, confirming the structure as 4 trifluoromethoxybenzothiazol-2-ylamine (5). 

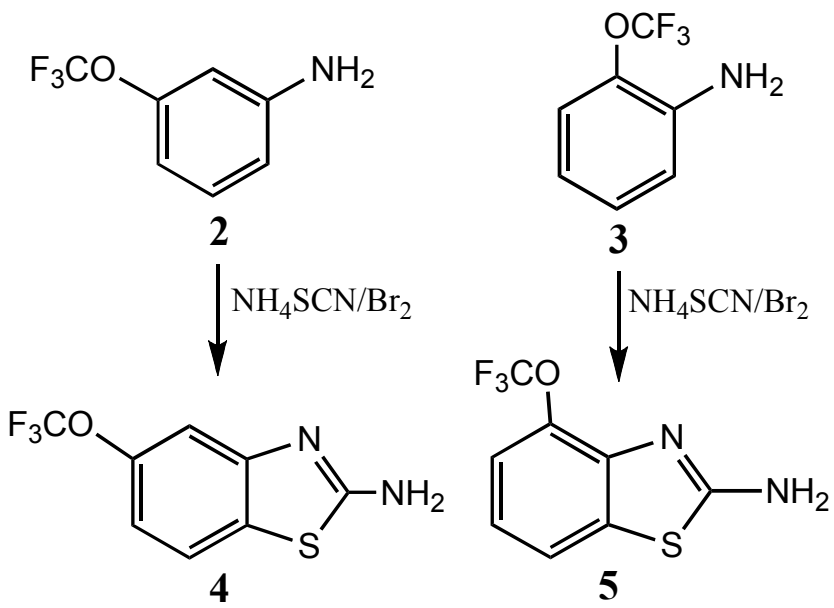

\section{Scheme 2}

4-Bromo-6-trifluoromethoxybenzothiazol-2-ylamine (6) was synthesized from riluzole by reacting with bromine (Scheme 3). The MS-CI spectrum of 6 displayed two isotopic $\mathrm{M}+1$ ions at $\mathrm{m} / \mathrm{z} 313$ and 315 with 1:1 intensity due to the presence of the bromine atom. The IR spectral pattern was similar to that of riluzole, in addition to that, a band at $637 \mathrm{~cm}^{-1}$ corresponding to C$\mathrm{Br}$ stretching was observed. In the ${ }^{1} \mathrm{H}$ NMR spectrum, two singlet signals were observed at $\delta=$ $7.34 \mathrm{ppm}$ and $\delta=7.45 \mathrm{ppm}$ with a single proton integration each. This spectral data is in conformity with 4-bromo-6-trifluoromethoxybenzothiazol-2-ylamine (6).

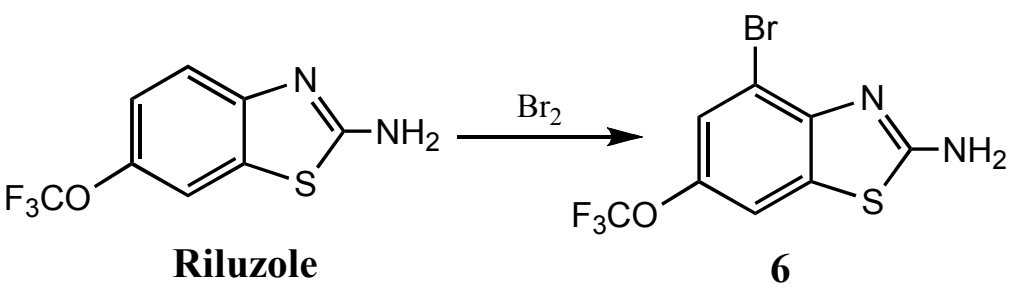

\section{Scheme 3}

2-Bromo-4-trifluoromethoxyphenylamine (7) was synthesized from $\mathbf{1}$, by reacting with 0.5 mole of bromine (Scheme 4). The MS-CI spectrum of 7 displayed two isotopic M+1 ions at $\mathrm{m} / \mathrm{z}$ 256 and 258 with 1:1 intensity, the IR spectrum was similar to that of $\mathbf{1}$, and a band at $638 \mathrm{~cm}^{-1}$ corresponding to $\mathrm{C}-\mathrm{Br}$ stretching was observed. A singlet signal at $\delta=7.46 \mathrm{ppm}$ and two doublets at $\delta=6.82 \mathrm{ppm}$ and $\delta=7.13 \mathrm{ppm}$ were observed in the ${ }^{1} \mathrm{H}$ NMR spectrum. Based on the spectral data, the structure was confirmed as 2-bromo-4-trifluoromethoxyphenylamine (7).

1,3-Bis-(4-trifluoromethoxyphenyl)thiourea (8) was synthesized from $\mathbf{1}$, by reacting with ammonium thiocyanate (Scheme 4). The mass spectrum of $\mathbf{8}$ displayed a protonated molecular ion at $\mathrm{m} / \mathrm{z}$ 397. The IR spectrum pattern was similar to that of $\mathbf{1}$, in addition to that a band at 
$1542 \mathrm{~cm}^{-1}$ was observed which was attributed to the $\mathrm{C}=\mathrm{S}$ stretching,. This spectral data confirms the structure of 1, 3-bis-(4-trifluoromethoxyphenyl)thiourea (8).

2,6-Dibromo-4-trifluoromethoxyphenylamine (9) was synthesized from 1 by reacting with 1.0 mole of bromine (Scheme 4). The MS-CI spectrum of 9 displayed three isotopic $\mathrm{M}+1$ ions at $\mathrm{m} / \mathrm{z} 334,336$ and 338 with 1:2:1 intensities due to the presence of two bromine atoms, and IR spectral pattern similar to that of 1 , and a band at $637 \mathrm{~cm}^{-1}$ corresponding to the $\mathrm{C}-\mathrm{Br}$. In the ${ }^{1} \mathrm{H}$ NMR spectrum, a two-proton singlet signal was observed at $\delta=7.65 \mathrm{ppm}$. This spectral data is in conformity with 2,6-dibromo-4-trifluoromethoxyphenylamine (9).

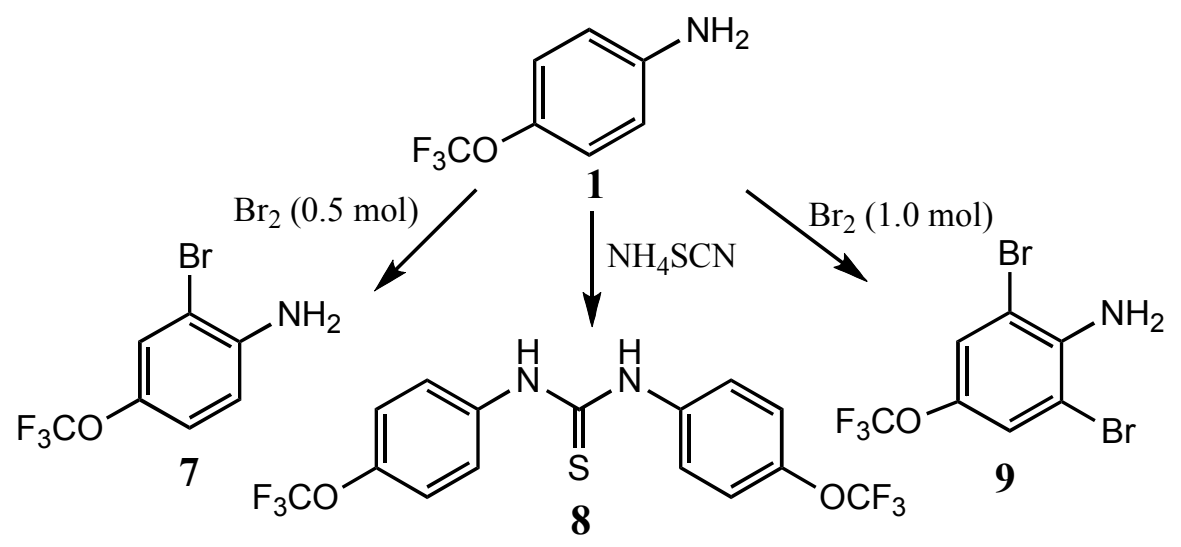

\section{Scheme 4}

\section{Conclusions}

The process related impurities in riluzole bulk drug were identified, synthesized, isolated and characterized by HPLC (analytical and preparative), MS, FT-IR and NMR $\left(1 \mathrm{H},{ }^{13} \mathrm{C}\right.$ and DEPT) techniques.

\section{Experimental Section}

General Procedures. The ${ }^{1} \mathrm{H}$ and ${ }^{13} \mathrm{C}$ NMR spectra were recorded on a Gemini $200 \mathrm{MHz}$ FT NMR spectrometer; the chemical shift values are reported in $\delta \mathrm{ppm}$ relative to TMS. The IR spectra were recorded in the solid state as $\mathrm{KBr}$ dispersions using a Perkin Elmer FT-IR spectrophotometer. The mass spectra were recorded on Shimadzu LCMS-QP8000, LC-MS and AB-4000 Q-trap LC-MS/MS. Elemental analysis for CHN were performed on Perkin Elmer model 2400 CHNS/O analyzer at Dr. Reddy's Laboratories Ltd., Hyderabad. 


\section{Procedure for the preparation of trifluoromethoxybenzothiazol-2-ylamines (4 and 5)}

To a mixture of the trifluoromethoxyphenylamine ( 2 or $3,10 \mathrm{~g}, 0.056 \mathrm{~mol})$ and acetic acid (46 $\mathrm{mL})$, ammonium thiocyanate $(10.7 \mathrm{~g}, 0.14 \mathrm{~mol})$ was added and the resulting mixture stirred in the range of -10 to $0{ }^{0} \mathrm{C}$ for $15-30$ minutes. Precooled bromine $(3.4 \mathrm{~mL}, 0.066 \mathrm{~mol})$ in glacial acetic acid $(20 \mathrm{~mL})$ was added to the mixture and maintained until reaction completion. Chilled water $(120 \mathrm{~mL})$ was added to the reaction mass at -10 to $0{ }^{0} \mathrm{C}$ and the resulting unwanted solid was filtered off and washed with water $(20 \mathrm{~mL})$. The filtrate was washed with toluene $(20 \mathrm{~mL})$ and aqueous layer $\mathrm{pH}$ adjusted to 8.5-9.5 with ammonia to produce a solid which was filtered, washed with water $(20 \mathrm{~mL})$, dried under vacuum at $70{ }^{\circ} \mathrm{C}$ and finally purified with a cyclohexane $(100 \mathrm{~mL})$ and toluene $(30 \mathrm{~mL})$ mixture to yield $11.3 \mathrm{~g}$ of title compounds 4 or 5 (yield: $85 \%$, HPLC purity $99 \%$ ).

5-Trifluoromethoxybenzothiazol-2-ylamine (4). IR $\left(\mathrm{cm}^{-1}\right): 3470(\mathrm{NH})$ and $3445(\mathrm{NH}) .{ }^{1} \mathrm{H}$ NMR (DMSO-d 6 , $\delta$ ppm): 6.23 (s, 2H, NH), 6.65 (d, 1H, Ar-H, J 8.60), 6.83 (s, 1H, Ar-H), 7.52 (d, 1H, Ar-H, $J$ 8.65). ${ }^{13} \mathrm{C}$ NMR (DMSO-d $\left.6, p p m\right): 165.34,144.05,134.02,127.02,122.95$, 117.83, 112.63, 105.45. MS-CI-m/z: $235\left(\mathrm{M}^{+1}\right)$. Analysis calcd. for $\mathrm{C}_{8} \mathrm{H}_{5} \mathrm{~F}_{3} \mathrm{~N}_{2} \mathrm{OS}$ : C, 41.03; $\mathrm{H}$, 2.15 ; N, 11.96\% Found: C, 41.12; H, 2.15; N, 12.11\%.

4-Trifluoromethoxy-benzothiazol-2-ylamine (5). IR $\left(\mathrm{cm}^{-1}\right): 3467(\mathrm{NH})$ and $3446(\mathrm{NH}) .{ }^{1} \mathrm{H}$ NMR (DMSO-d 6 , $\delta$ ppm): 6.24 (s, 2H, NH), 6.92 (d, 1H, Ar-H J 8.45), 7.32 (dd, 1H, Ar-H, $J$ 8.75), 7.54 (d, 1H, Ar-H, J 8.85). ${ }^{13} \mathrm{C}$ NMR (DMSO-d 6, ppm): 158.89, 149.57, 137.21, 122.47, 113.26, 111.67, 105.54, 96.97. MS-CI $\mathrm{m} / z: 235\left(\mathrm{M}^{+1}\right)$. Analysis calcd. for $\mathrm{C}_{8} \mathrm{H}_{5} \mathrm{~F}_{3} \mathrm{~N}_{2} \mathrm{OS}$ : C, 41.03; H, 2.15; N, 11.96\% Found: C, 40.94; H, 2.12; N, 12.04\%.

4-Bromo-6-trifluoromethoxybenzothiazol-2-ylamine (6). To a mixture of riluzole (2 g, 0.0085 mol) and acetic acid $(40 \mathrm{~mL})$, precooled bromine $(0.44 \mathrm{~mL} 0.0085 \mathrm{~mol})$ was added and the mixture heated at $50{ }^{\circ} \mathrm{C}$ till reaction completion. The reaction mixture was cooled to $25-35{ }^{\circ} \mathrm{C}$, water $(50 \mathrm{~mL})$ was added. The resulting solid was filtered, washed with water $(10 \mathrm{~mL})$ and dried at $60{ }^{\circ} \mathrm{C}$ under vacuum to yield $2.4 \mathrm{~g}$ of title compound 6 (yield: 90\%, HPLC purity 99\%). IR $\left(\mathrm{cm}^{-1}\right): 3347(\mathrm{NH}), 3369(\mathrm{NH})$ and 637. ${ }^{1} \mathrm{H}$ NMR (DMSO-d $\left.6, \delta \mathrm{ppm}\right): 5.48(\mathrm{~s}, 2 \mathrm{H}, \mathrm{NH}), 7.34(\mathrm{~s}$, $1 \mathrm{H}, \mathrm{Ar}-\mathrm{H}), 7.45$ (s, 1H, Ar-H). ${ }^{13} \mathrm{C} \mathrm{NMR}$ (DMSO-d $\left.{ }_{6}+\mathrm{CDCl}_{3}, \mathrm{ppm}\right): 169.34,143.64,139.61$, 127.26, 122.98, 119.01, 114.63 106.65. MS-CI m/z: 313 and $315(\mathrm{M}+1)$. Analysis calcd. for $\mathrm{C}_{8} \mathrm{H}_{4} \mathrm{BrF}_{3} \mathrm{~N}_{2} \mathrm{OS}$ : C, 30.69; H, 1.29; N, 8.95\% Found: C, 30.78; H, 1.32; N, 8.99\%.

2-Bromo-4-trifluoromethoxy-phenylamine (7). To a mixture of 4trifluoromethoxyphenylamine $(1,30 \mathrm{~g}, 0.169 \mathrm{~mol})$ and methanol $(120 \mathrm{~mL})$, aluminum chloride $(0.22 \mathrm{~g}, 0.0016 \mathrm{~mol})$ was added and the mixture stirred in the range of 0 to $10{ }^{0} \mathrm{C}$. Precooled bromine $(4.3 \mathrm{~mL}, 0.085 \mathrm{~mol})$ was added to the reaction mixture in the range of 0 to $10{ }^{0} \mathrm{C}$ and this temperature maintained until the reaction was complete. Water $(200 \mathrm{~mL})$ was added to the reaction mixture at $5{ }^{0} \mathrm{C}$ and the product was extracted into dichloromethane $(2 \times 100 \mathrm{~mL})$, followed by washing with water $(2 \times 50 \mathrm{~mL})$. The organic layer was concentrated under vacuum and the residual material was triturated with cyclohexane $(80 \mathrm{~mL})$ to afford $37.6 \mathrm{~g}$ of the title compound 7 (yield: 87\%, HPLC purity 97\%). IR ( $\left.\mathrm{cm}^{-1}\right): 3328(\mathrm{NH})$ and $3372(\mathrm{NH}) .{ }^{1} \mathrm{H}$ NMR (DMSO-d $\mathrm{D}_{6}, \delta$ ppm): 5.29 (s, 2H, NH), 6.82 (s, 1H, Ar-H), 7.13 (d, 1H, Ar-H, J 8.70) 7.46 (d, 1H, 
Ar-H, $J$ 8.75). ${ }^{13} \mathrm{C}$ NMR (DMSO-d 6 , ppm): 154.32, 142.35, 121.34, 119.85, 117.25, 114.32, 110.72. MS-CI $m / z: 256$ and $258\left(\mathrm{M}^{+1}\right)$. Analysis calcd. for $\mathrm{C}_{7} \mathrm{H}_{5} \mathrm{BrF}_{3} \mathrm{NO}: \mathrm{C}, 32.84 ; \mathrm{H}, 1.97 ; \mathrm{N}$, 5.47\% Found: C, 32.93; H, 1.98; N, 5.57\%.

1,3-Bis-(4-trifluoromethoxy-phenyl)-thiourea (8). To a mixture of ammonium thiocyanate (4.4 $\mathrm{g}, 0.057 \mathrm{~mol})$ and $20 \% \mathrm{HCl}(12 \mathrm{~mL})$, sodium bisulfite $(0.4 \mathrm{~g})$, TFMA (1, $10 \mathrm{~g}, 0.056 \mathrm{~mole})$ was added and the mixture maintained for $30 \mathrm{~min}$ at $25-35{ }^{0} \mathrm{C}$ then at $90-95{ }^{0} \mathrm{C}$ for $10-12 \mathrm{~h}$. The reaction mixture was cooled to $25-35{ }^{\circ} \mathrm{C}$ and the aqueous layer decanted. Diisopropyl ether $(50$ $\mathrm{mL}$ ) was added to the residue and stirred at $25-35{ }^{\circ} \mathrm{C}$ for $1-2 \mathrm{~h}$. The resulting solid was filtered, washed with diisopropyl ether $(10 \mathrm{~mL})$ and dried at $25-35{ }^{0} \mathrm{C}$ overnight to afford $17.9 \mathrm{~g}$ of title compound 8 (yield: 80\%, HPLC purity 96\%). IR $\left(\mathrm{cm}^{-1}\right)$ : $1542(\mathrm{C}=\mathrm{S}) ;{ }^{1} \mathrm{H}$ NMR (DMSO-d 6 ppm): 4.5 (s, 2H, NH), 6.5 (d, 4H, Ar-H, J 9.55), 6.9 (d, 4H, Ar-H, J 9.50). ${ }^{13} \mathrm{C}$ NMR (DMSO-d 6 , ppm): 180.01, 144.67, 144.69, 138.53, 125.23, 125.01, 121.38, 121.14, 118.83. MS-CI m/z: 397 $\left(\mathrm{M}^{+1}\right)$. Analysis calcd. for $\mathrm{C}_{15} \mathrm{H}_{10} \mathrm{~F}_{6} \mathrm{~N}_{2} \mathrm{O}_{2} \mathrm{~S}: \mathrm{C}, 45.46 ; \mathrm{H}, 2.54 ; \mathrm{N}, 7.07 \%$ Found: $\mathrm{C}, 45.57 ; \mathrm{H}$, 2.55; N, 7.17\%.

2,6-Dibromo-4-trifluoromethoxy-phenylamine (9). To a mixture of 4-trifluoromethoxyphenylamine $(1,30 \mathrm{~g}, 0.169 \mathrm{~mol})$ and methanol $(120 \mathrm{~mL})$, aluminum chloride $(0.22 \mathrm{~g}, 0.0016$ mol) was added under stirring at $0-10{ }^{0} \mathrm{C}$. Precooled bromine $(8.6 \mathrm{~mL}, 0.169 \mathrm{~mol})$ was added at $0-10{ }^{0} \mathrm{C}$ and the mixture maintained at $25-35{ }^{\circ} \mathrm{C}$ until the reaction was complete. Water $(200 \mathrm{~mL})$ was added at $5{ }^{0} \mathrm{C}$ and the product extracted into dichloromethane $(2 \times 100 \mathrm{~mL})$. The organic extract was washed with water $(2 \times 50 \mathrm{~mL})$ and concentrated under vacuum, and the residual mass was triturated with cyclohexane $(100 \mathrm{~mL}$ ) to afford the $48 \mathrm{~g}$ of the title compound 9 (yield: $85 \%$, HPLC purity 97\%); IR $\left(\mathrm{cm}^{-1}\right): 3338(\mathrm{NH})$ and $3369(\mathrm{NH}) .{ }^{1} \mathrm{H}$ NMR (DMSO-d $6, \delta$ ppm): 5.34 (s, 2H, NH), 7.65 (s, 2H, Ar-H). ). ${ }^{13} \mathrm{C}$ NMR (DMSO-d 6 , ppm): 149.32, 141.35, 138.22, 117.24 , 116.34, 114.45, 111.38. MS-CI $m / z: 334,336$ and $338(\mathrm{M}+1)$. Analysis calcd. for $\mathrm{C}_{7} \mathrm{H}_{4} \mathrm{Br}_{2} \mathrm{~F}_{3} \mathrm{NO}$ : C, 25.10; H, 1.20; N, 4.18\% Found: C, 25.23; H, 1.17; N, 4.22\%.

\section{Acknowledgements}

The authors wish to thank the management of Dr. Reddy's Laboratories Ltd., IPDO-API for supporting this work.

\section{References}

1. Jacques, M.; Villeneuve, 1. G. U.S. Patent 4,370,338, 1983; Chem. Abstr. 1964, 60, 692a.

2. Yagupolskii, L. M.; Gandelsman, L. Zh. Obshch. Khim. 1963, 33, 2318.

3. Bensimon, G.; Lacomblez, L.; Meininger, V; and the ALS riluzole study group. N. Engl. J. Med. 1994, 330, 585.

4. Phukan, J.; Pender, N. P.; Hardiman, O. Lancet Neurol. 2007, 6 (11), 994.

5. ICH Guideline Q3A (R), Impurities in New Drug Substances, 7 February, 2002. 